\title{
Comparative histomorphology and histochemistry of thoracic aorta in deccani sheep and bidri goat
}

\begin{abstract}
Thoracic aorta were elastic type, tunica intima consisted of a single layer of flattened endothelial cells, sub endothelial layer and indistinct internal elastic membrane. Tunica media is thickest among the three layers and well-defined elastic lamellae, they were separated by circularly arranged smooth muscle, collagen fibers and reticular fibers. External elastic membrane was not distinguishable from many elastic layers in tunica media and tunica adventitia was comprised of collagen fibers, elastic fibers, vasa vasorum and fibroblasts in loose connective tissue. Histochemically thoracic aorta of both the species showed strong (+++) PAS positive in the tunica intima of Bidri goat and Deccani sheep. Tunica media showed moderate $(++)$ alcian blue $(\mathrm{pH} 1.0)$ reaction in sheep, whereas, in goat it was strong $(+++)$ alcian blue reaction and tunica adventitia was strong $(+++)$ PAS positive in Deccani sheep whereas, in goat it was strong $(+++)$ alcian blue positive.
\end{abstract}

Volume 2 Issue 3 - 2016

\begin{abstract}
Sharanagouda, Ashok p, Dilipkumar D, Shrikanth Kulkarni Girish MH, Mahantesh Department of Veterinary Anatomy and Histology, Veterinary College KVAFSU, India
\end{abstract}

Correspondence: Sharanagouda, Veterinary officer Veterinary Dispensary Madiyal,TQ-Aland Dist-Kalaburagi, Karnataka, India, Email sharan645@gmail.com

Received: October 7, 2015 | Published: March 30, 2016

Keywords: histology, histochemistry, thoracic aorta, sheep, goat

\section{Introduction}

Small ruminant population in India is about 212.1 million. In that sheep population is about $71.6 \mathrm{million}$ and goat population is about 140.5 million and it contributes $10 \%$ GDP to the total value of livestock sector. ${ }^{1}$ The small ruminant population in Bidar district is 2,73,664 in that goat population is about $1,89,003$ and sheep population is about 84,661 . The predominant breeds in Bidar district is Bidri goat and Deccani sheep. Blood vessels regulate the blood flow to all parts of the body tissue, larger blood vessels involve in conducting system whereas, smaller arteries and capillaries take part in regulatory and nutrient activity. Mechanical properties of blood vessels are dictated by the vessel wall structure. Thoracic aorta made up of three layers, they are termed from inner to outer as tunica intima, tunica media and tunica adventitia (tunica externa). Wall thickness of the different blood vessels also may vary according to their location with regard to specific species. ${ }^{2}$ Thoracic aorta made up of three layers, they are termed from inner to outer are tunica intima, tunica media and tunica adventitia (tunica externa). The structure of the thoracic aorta is elastic type. ${ }^{3}$ Thoracic aorta is a large conducting artery and details of its histological organization and histochemical reaction in Deccani sheep and Bidri goat are limited in literature, hence the present research work has been undertaken with the following objectives.

i. To study the histo-morphology of the Thoracic aorta in Deccani sheep and Bidri goat.

ii. To correlate any structural variations of Thoracic aorta in Deccani sheep and Bidri goat.

\section{Material and methods}

The material for the study were collected from Eight adult Deccani sheep and Bidri goat immediately after slaughter from local slaughter houses in bidar. The collected tissue pieces were washed in normal saline later, they were fixed in different fixatives and they were processed and embedded in paraffin by routine method. Sections were cut at 4-6 $\mu \mathrm{m}$ thickness and were utilized for histomorphological, histometrical study and histochemical studies. Various staining methods like Mayer's haemalum-eosin-phloxine method, ${ }^{4}$ Mallory's phosphotungstic acid haematoxylin method for connective tissue and muscle fibers, ${ }^{4}$ Masson's trichrome method for connective tissue and muscle fibers, ${ }^{4}$ Van Geison's stain for Collagen fibers, ${ }^{4}$ Gomori's aldehyde fuschin method for Elastic fibers, ${ }^{4}$ Verhoeff's method for Elastic fibers, ${ }^{5}$ Gomori's method for Reticulum fibers, ${ }^{4}$ PAS-Alcian blue (pH1.0) method for mucosubstances, ${ }^{4}$ PAS method for mucosubstances ${ }^{4}$ were adopted to study the histology and histochemistry.

\section{Statistical analysis}

The histometrical parameters of thoracic arteries of Deccani sheep and Bidri goat. Were measured with the help of ocular micrometer and data obtained was statistical analyzed by procedure of Snedecor and Cochron. ${ }^{6}$

\section{Results}

\section{Sheep}

Histomorphology: Thoracic aorta of adult Deccani sheep was an elastic artery, consisted of three layers namely tunica intima, tunica media and tunica adventitia (Figure 1). Thickness of total thoracic aortic wall and different layers are presented in Table 1. Tunica intima consisted of thin endothelium, sub endothelial layer consist of elastic fibers, collagen fibers, reticular fibers and fibroblasts Elastic core containing internal elastic membrane and it is not distinguishable from elastic lamellae of media (Figure 2) (Figure 3). Tunica media is thickest $(954.80 \pm 59.15 \mu \mathrm{m})$ among three layers, it consisted of circularly arranged smooth muscle fibers, each layer of smooth muscle fiber attached to elastic lamellae (Figure 4) (Figure 5). The number of elastic lamellae are ranged from 20-22 and they were intercalated with smooth muscle cells and collagen fibers and reticular fibers (Figure 6) form a delicate network around the individual smooth muscle fibers. Outer part of tunica media consists of longitudinally arranged smooth muscle bundles and indistinct external elastic membrane, which is made up of elastic fibers. Tunica adventitia was contained bundles of collagen fibers with intermixed elastic fibers (Figure 4) (Figure 6), vasa vasorum and fibroblasts in the loose connective tissue. 
Histochemistry: The thoracic aorta of adult Deccani sheep showed strong $(+++)$ PAS reaction in tunica intima, tunica adventitia and moderate $(++)$ alcian blue $(\mathrm{pH} 1.0)$ reaction in tunica media (Figure 7) (Figure 8).

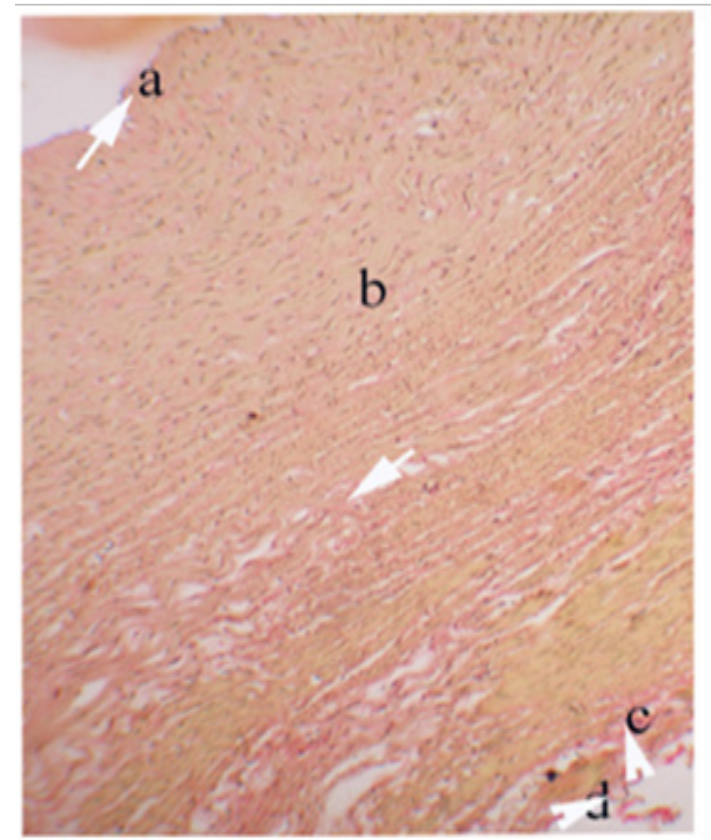

Figure I Photomicrograph of thoracic arota showing tunica intima (A), tunica media $(B)$ and tunica adventia $(C)$ and collagen fibers $(=)$ in tunica intima $(A)$, tunica media $(B)$, tunica adventia $(C)$ and Vasavasorum $(D)$ in the tunica adventia of adult Bidri goat.

Van Gieson's Stain X 10.

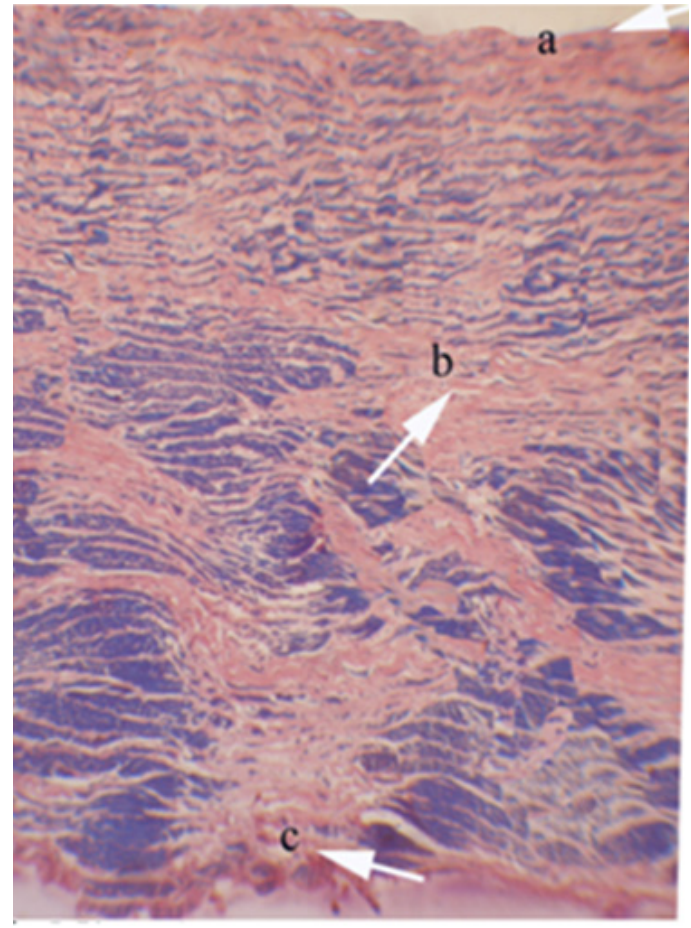

Figure 2 Photomicrograph of thoracic arota showing tunica intima (A), tunica media (B) and tunica adventia (C) and collagen fibers (arrow) in tunica intima (A), tunica media (B) and tunica adventia (C) in adult Deccani shhep. Mallory's Phosphotungastic Acid Haematoxylin X 10.

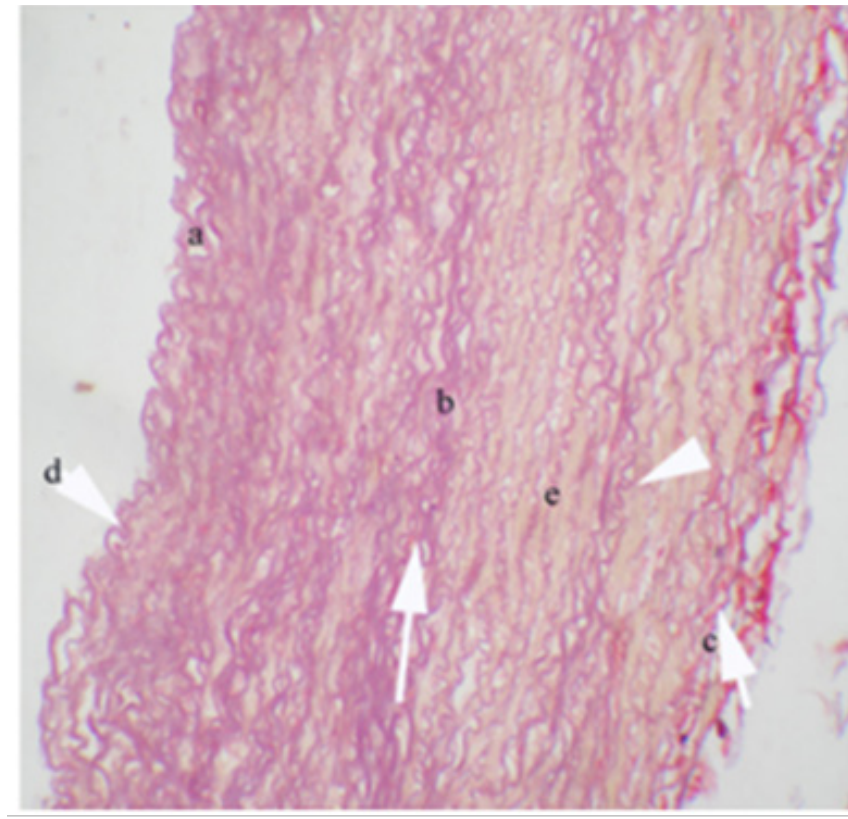

Figure 3 Photomicrograph of thoracic aorta showing elastic fibres (arrow) in tunica intima (A), tunica media (B) and tunica adventia (C) and internal elastic membrane (D), elastic lamellae (E) between smooth muscle bundles of tunica media of the tunica adventia of adult Bidri goat. Gomri's Aldehyde Fucschin X 10.

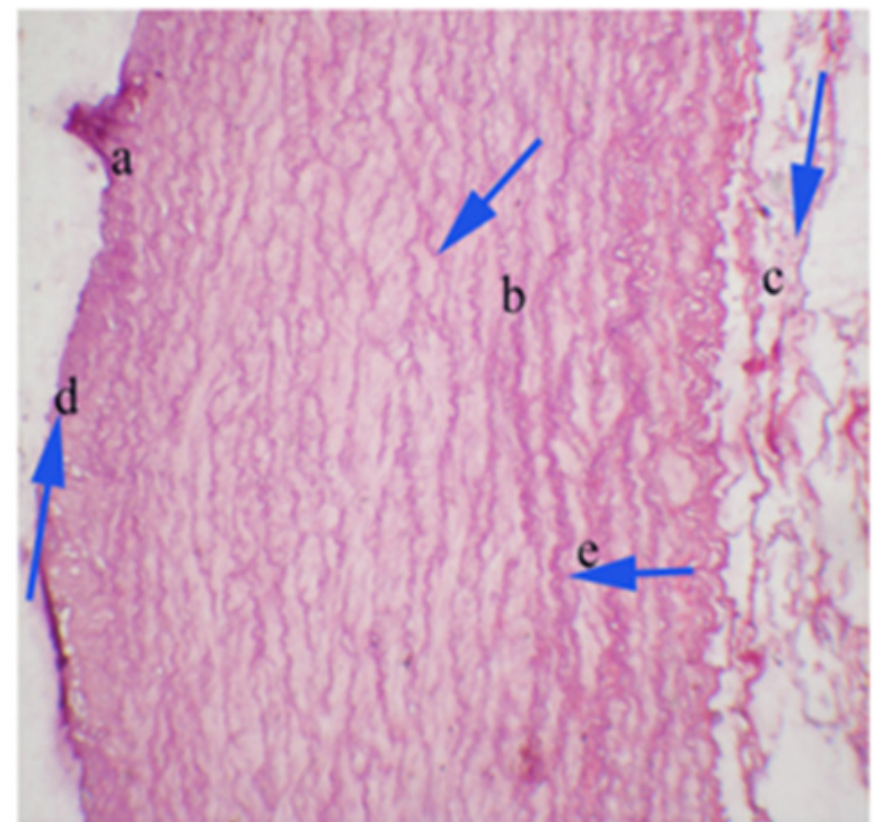

Figure 4 Photomicrograph of thoracic aorta showing elastic fibres (arrow) in tunica intima (A), tunica media (B) and tunica adventia (C) and internal elastic membrane (D), elastic lamellae (E) between smooth muscle bundles of tunica media of the tunica adventia of adult Bidri goat. Gomri's Aldehyde Fucschin X 10.

\section{Goat}

Histomorphology: Thoracic aorta of adult Bidri goat was an elastic artery, which consisted of three layers namely tunica intima, tunica media and tunica adventitia (Figure 9) (Figure 10). Thickness of total thoracic aortic wall and different layers are presented in Table 1. Tunica intima consisted of thin endothelium, sub endothelial layer 
consist of elastic fibers, collagen fibers, reticular fibers and fibroblasts (Figure 1). Elastic core containing internal elastic membrane and it is not distinguishable from elastic lamellae of media. Tunica media is thickest $(905.67 \pm 31.73 \mu \mathrm{m})$ among three layers and consisted of circularly arranged smooth muscle fibers, each layer of smooth muscle fiber attached to elastic lamellae (Figure 3). The number of elastic lamellae ranged from 20-22 and they were intercalated with smooth muscle cells and collagen fibers and reticular fibers form a delicate network around the individual smooth muscle fibers (Figure 5). Outer part of tunica media consisted of longitudinally arranged smooth muscle bundles and indistinct external elastic membrane, which is made up of elastic fibers. Tunica adventitia was contained bundles of collagen fibers with intermixed elastic fibers, vasa vasorum and fibroblasts in the loose connective tissue (Figure 5).

Histochemistry: The thoracic aorta of adult Bidri goat showed strong $(+++)$ PAS reaction in tunica intima, strong $(+++)$ alcian reaction blue $(\mathrm{pH} 1.0)$ in the tunica media and tunica adventitia (Figure 7).

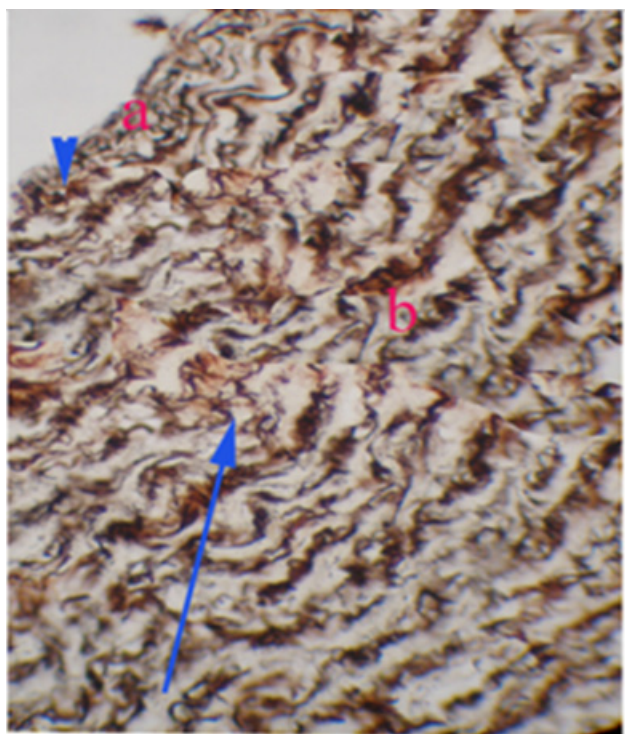

Figure 5 Photomicrograph of thoracic aorta showing reticular fibres (arrow) in subendothelial layer (A) and tunica media (B) of adult Bidri goat. Gomori's Method X 10.

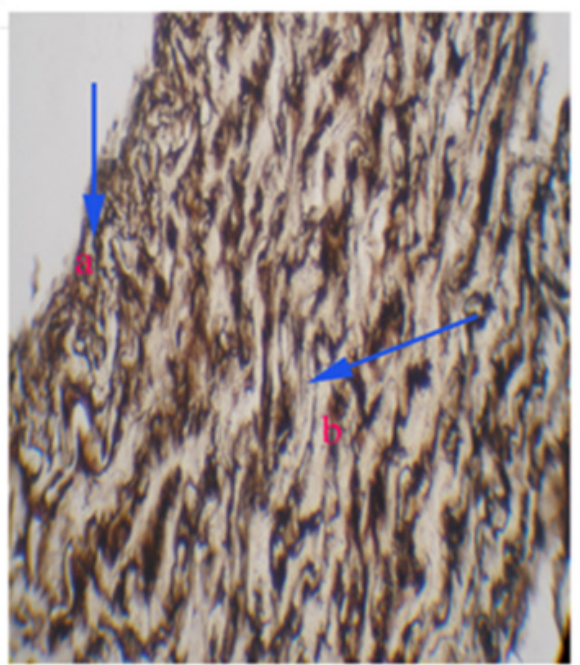

Figure 6 Photomicrograph of thoracic aorta showing reticular fibres (arrow) in subendothelial layer (A) and tunica media (B) of adult Deccani sheep. Gomori's Method X 10.

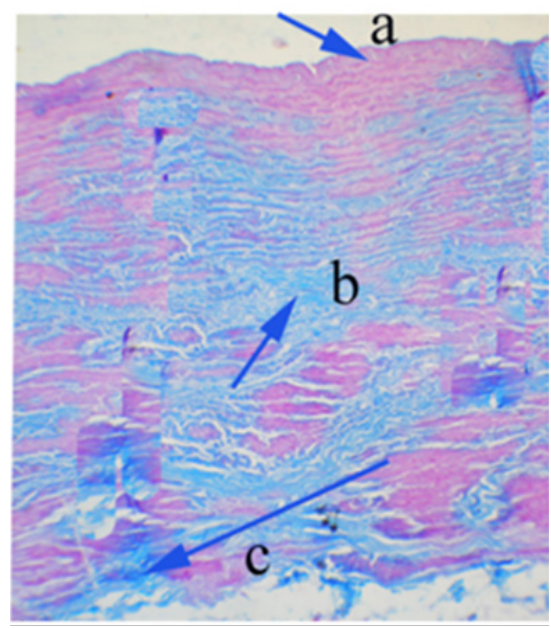

Figure 7 Photomicrograph of a thoracic aorta showing strong PAS positive reaction in tunica intima $(A)$, strong alcian blue $(\mathrm{Ph} I .0)$ reaction in tunica media $(B)$ and strong alcian blue $(\mathrm{Ph} \mathrm{I.0)}$ reaction in tunica adventia $(\mathrm{C})$ of adult Bidrigoat.

PAS-Alcian Blue (Ph I.0) Method X 10

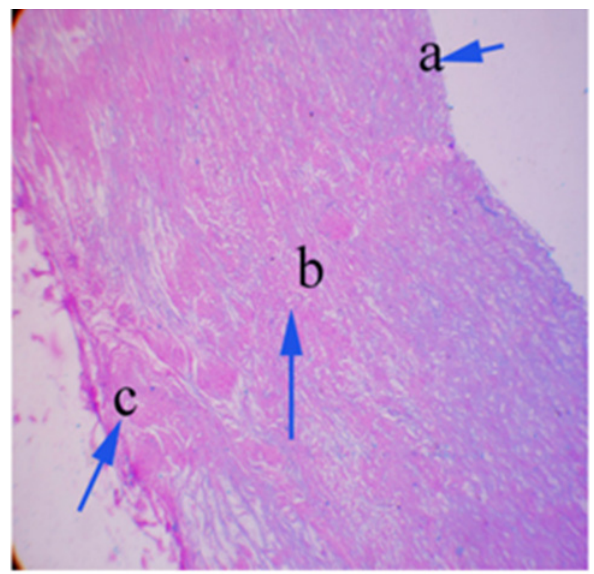

Figure 8 Photomicrograph of a Thoracic aorta showing strong PAS positive reaction in tunica intima $(A)$,

moderate alcian blue $(\mathrm{Ph}$ I.0) reaction in tunica media $(\mathrm{B})$ and strong PAS positive $(\mathrm{Ph}$ I.0) reaction in tunica adventia (C) of adult Deccani sheep.

PAS-Alcian Blue (Ph I.0) Method X 10

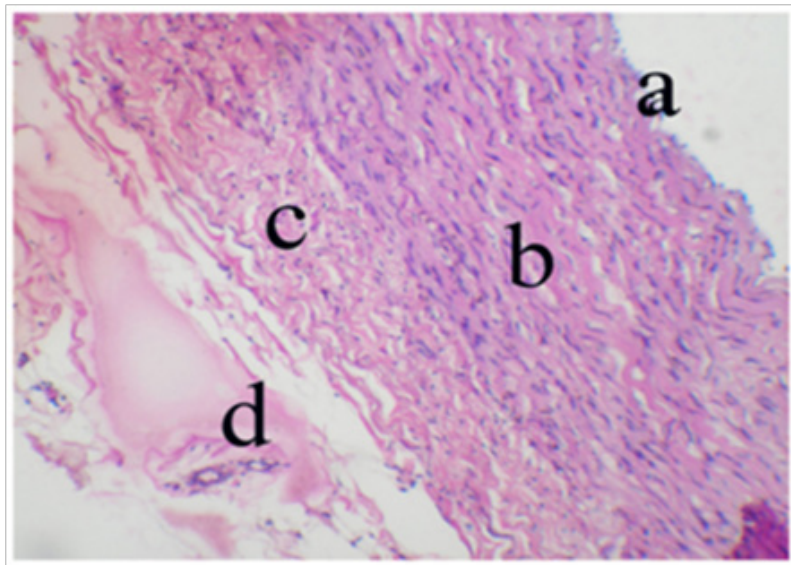

Figure 9 Photomicrograph of thoracic aorta showing tunica intima $(A)$, tunica media (B), tunica adventia (C) and vasavasorum (D) of adult Bidri goat.

$H \& E \times 10$ 


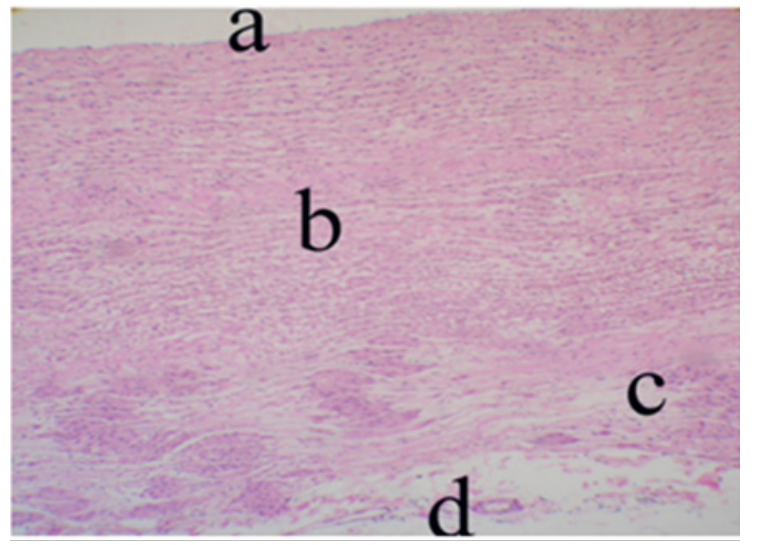

Figure 10 Photomicrograph of thoracic aorta showing tunica intima (A), tunica media (B), tunica adventia (C) and vasavasorum (D) of adult Deccani sheep. $H \& E X 10$

Table I Mean \pm standard error of thickness $(\mu \mathrm{m})$ of total wall and tunics of thoracic aorta in adult deccani sheep and bidri goat

\begin{tabular}{llll}
\hline & Total wall & $1089.56 \pm 19$ & $1034.76 \pm 42.88$ \\
Thoracic aorta & Intima & $19.64 \pm 0.39$ & $19.34 \pm 0.54$ \\
\cline { 2 - 3 } & Media & $954.80 \pm 59.15$ & $905.67 \pm 31.73$ \\
& Adventitia & $115.13 \pm 12.00$ & $109.75 \pm 16.34$ \\
\hline
\end{tabular}

\section{Discussion}

\section{Histomorphology}

In the present study thoracic aorta of adult Deccani sheep and Bidri goat consisted of all the three layers namely, tunica intima, tunica media and tunica adventitia. Mello et al. ${ }^{7}$ in dog, Moustafa ${ }^{8}$ in rats and Ogeng'o et al. ${ }^{9}$ in adult goats where they had reported the presence of all the layers in the thoracic aorta. In the present study thoracic aorta of adult Deccani sheep and Bidri goat was an elastic artery. These findings are similar to the reports of Awal et al. ${ }^{3}$ in guinea pig, Prodan et al. ${ }^{10}$ in dog, Trautmann \& Fiebiger ${ }^{11}$ in domestic animals, Mello et al. ${ }^{7}$ in dog. Mello et al. ${ }^{7}$ reported thickness of tunica intima was $4.03 \mu \mathrm{m}$, tunica media layer was $218.1 \mu \mathrm{m}$ and tunica adventitia was $202.5 \mu \mathrm{m}$ in the thoracic aorta of guinea pig, whereas, it was 2.68 $\mu \mathrm{m}, 202.5 \mu \mathrm{m}$ and $57.9 \mu \mathrm{m}$ in rats respectively and tunica media was thickest among three layers. However, in the present study thickness of is tunica intima is $19.64 \pm 0.39 \mu \mathrm{m}$, tunica media was $954.80 \pm 59.15$ $\mu \mathrm{m}$ and tunica adventitia was $115.3 \pm 12.00 \mu \mathrm{m}$ in thoracic aorta of adult Deccani sheep, whereas, in adult Bidri goat it was $19.34 \pm 0.54$ $\mu \mathrm{m}, 905.67 \pm 31.73 \mu \mathrm{m}$ and $109.75 \pm 16.34 \mu \mathrm{m}$ respectively. There was no significant difference between thickness of the individual layers and total wall. Tunica media was thickest is an agreement with their observation and thickness of tunica media is due to more numbers of elastic fibers. In the present study tunica intima of thoracic aorta consisted of thin endothelium, sub endothelial layer made up of collagen, elastic, reticular fibers with indistinct internal elastic membrane in adult Deccani sheep and Bidri goat. These finding are similar to the earlier reports of Awal et al. ${ }^{3}$ in guinea pig, Mello et al. ${ }^{7}$ in dog, Samuelson ${ }^{2}$ in domestic animals, and Ogeng'o et al. ${ }^{9}$ in adult goats. In the present study tunica media of thoracic aorta is thickest among three layers, it consisted of multiple layer of concentrically arranged smooth muscle fibers, each layer of smooth muscle fiber attached to elastic lamellae. Elastic lamellae are intercalated with smooth muscle cells and collagen bundles. The number of elastic lamellae ranged from 20-22 and reticular fibers formed delicate network around the individual smooth muscle fibers and outer most part of tunica media was indistinct external elastic membrane which is made up of elastic fibers and longitudinally arranged smooth muscle bundles in adult Deccani sheep and Bidri goat. These findings are in agreement with the report of Trautmann \& Fiebiger ${ }^{11}$ in domestic animals, Mello et al. ${ }^{7}$ in dog, Moustafa ${ }^{8}$ in rats and Ogeng'o et al. ${ }^{9}$ in adult goats however, it differ with the number of elastic lamellae, as reported by in Awal et al..$^{3}$ in guinea pig and Prodan et al. ${ }^{10}$ in dog numbers of elastic lamellae where 10-15 and Mello et al. ${ }^{7}$ reported high amount of elastic lamellae in the tunica media of thoracic aorta in dog. In the present study tunica adventitia of thoracic aorta composed of elastic and collagen fibers with vasavasorum in adult Deccani sheep and Bidri goat. These findings are similar to the reports of Awal et al. ${ }^{3}$ in guinea pig, Prodan et al. ${ }^{10}$ in dog, Trautmann \& Fiebiger ${ }^{11}$ in domestic animals, Mello et al. ${ }^{7}$ in dog, Moustafa ${ }^{8}$ in rats and Ogeng'o et al. ${ }^{9}$ in adult goats.

\section{Histochemistry}

In the present study thoracic aorta showed strong (+++) PAS positive in the tunica intima of Bidri goat and Deccani sheep. Tunica media showed moderate $(++)$ alcian blue $(\mathrm{pH} 1.0)$ reaction in sheep, whereas, in goat it was strong $(+++)$ alcian blue reaction and tunica adventitia was strong $(+++)$ PAS positive in Deccani sheep whereas, in goat it was strong $(+++)$ alcian blue positive. PAS positive indicating present of mucosubstances and strong alcian blue $(\mathrm{pH}$ 1.0) reaction indicates presence high sulfated glycosaminoglycans and mucins and it is similar to the earlier reports of Trautmann \& Fiebiger, ${ }^{11}$ Dellmann ${ }^{12}$ in domestic animals and Bartholomev et al. ${ }^{13}$ Proteoglycan containing chondroitin sulphate and dermatin sulfate was associated with elastic lamellae which shows intense reaction of alcian blue reported by Bartholomev et al. ${ }^{13}$ in bovine thoracic aorta and variation in the reaction of PAS- Alcian blue in Deccani sheep and Bidri goat is due to chemical nature of in these animal.

\section{Conclusion}

The present study revealed histology and histochemistry of thoracic arota Deccani sheep ad Bidri goat with little variation than that of other domestic animals. Statistically there was no significant difference in the thickness of total wall and individual layers in thoracic aorta in Bidri goat and Deccani sheep, little variation in the histochemistry of thoracic aorta of Bidri goat contained more sulfated mucosubstances compare to Deccani sheep. Thoracic aorta of Bidri Goat and Deccani sheep is an elastic artery, it contain more amount of elastic fibers compared to smooth muscle and collagen fibers. Elasticity of arteries depend up on amount of elastic fibers in the tunica media and arterial expansion is directly proportional to arterial elasticity and presence of more amount of elastic fibers they serves as a large conducting tubes and also facilitate the movement of blood along the tube throughout the body. Increased in the thickness of tunica intima and tunica media is an earlier sign of arthrosclerosis.

\section{Acknowledgements}

None.

\section{Conflict of interest}

Author declares that there is no conflict of interest.

\section{References}

1. Birthal PS, Taneja VK. Livestock food security and rural poverty. Economic and political weekly. 2003. 17p. 
2. Samuelson Don A. Textbook of Veterinary Histology. Missouri: Sauders elesiver; 2007. p. 209-223.

3. Awal MA, Mahammad Abdul AP, Masamichi Kurohmaru, et al. Microscopic study on the arterial walls of main arteries supplying the mammary glands of guinea pig (Cavia porcellus) at different reproductive stages. Vet Arhiv. 2001;71(1):19-30.

4. Luna LG. Manual of histological staining methods of armed forces of institute of pathology. 3rd ed. New York: McGraw Hill book co; 1968:72-99.

5. Bancroft Jhon D, Suvarna KIM S, Christopher Layton. Bancroft's theory and practice of histological techniques. 6th ed. Churchill livingstone, Elsevier; 2008. p. 187-241.

6. Snedecor GW, Cochran WG. Statisticical Methods. 11th ed. New Delhi: Oxford and IBH publishing Co.Pvt. Ltd; 1994:40-43.

7. Mello JM, Orisi MA, Padovani RC, et al. Structure of the aortic wall in the guinea pig and rat. Braz J MorpHol sci. 2004;21(1):35-38.
8. Moustafa AMAL M. Light and electron microscope study of thoracic aorta in premature menopause-induced rats and the possible role of ginger. Egypt J Histol. 2010;33(1):114-126.

9. Ogeng'O JA, Malek AK, Kiama SG. Regional differences in Aorta of goat (Capra hircus). Folia Morphol (Warsz). 2010;69(4):253-257.

10. Prodan MAA, Islam RM, Das MA, et al. Microscopic study on the arterial walls of main arteries supplying the mammary glands of dogs (Canis familiaris) in Bangladesh. Pak J Bio sci. 2001;4(12):1568-1571.

11. Trautmann A, Feibiger J. Fundamentals of Histology of Domestic Animals. Ithaca, New York: Livestock Publishing Associate; 2002. p. $106-119$.

12. Dellmann HD. Text Book of Veterinary Histology. In: Lea, Febiger, editors. 6th ed. Philadelphia, USA; 2006. p. 117-132.

13. Bartholomew JS, Bartholomew, John C Anderson. Distribution of Proteoglycan and hyaluronic acid in transverse section of bovine thoracic aorta. J Mol Histol 1983;15(10):941-951. 